\title{
Effect Of Flyash On The Mechanical, Thermal, Dielectric, Rheological And Morphological Properties Of Filled Nylon 6
}

\author{
${ }^{1}$ Suryasarathi Bose and ${ }^{2}$ P.A.Mahanwar \\ Plastics \& Paints Division University Institute of Chemical Technology, \\ Matunga, Mumbai-400 019, India. \\ Phone: 91-22-24106695 ${ }^{1}$ E-mail: bose154@rediffmail.com ${ }^{2}$ E-mail: pmahanwar@yahoo.com
}

\begin{abstract}
:
Fillers are used along with various commodities as well as engineering polymers to improve the properties of polymers. The performance of filled polymers is generally determined on the basis of the interface attraction of filler and polymers. Fillers of widely varying particle size and surface characteristics are responsive to the interfacial interactions with polymers. The present study deals with the effect of particle size and its concentration on the properties of flyash filled nylon 6.
\end{abstract}

Keywords: nylon 6, flyash, composites, mechanical properties, thermal properties, dielectric properties, rheological properties, morphological properties.

\section{Introduction}

Particle filled polymer composites have become attractive because of their wide applications and low cost. Incorporating inorganic mineral fillers into plastic resin improves various physical properties of the materials such as mechanical strength, modulus and heat distortion temperature. In general the mechanical properties of particulate filled polymer composites depend strongly on size, shape and distribution of filler particles in the matrix polymer and good adhesion at the interface surface. Nylons are one of the most widely used engineering thermoplastics utilized in automobile, electrical, electronic, packaging, textiles and consumer applications because of their excellent mechanical properties. However limitations ${ }^{1-6}$ in mechanical properties, such as the low heat distortion temperature, high water absorption and dimension instability of pure nylons have prevented their applications in structural components. Hence numerous efforts have been undertaken to use nylons as matrix resins for composites by adding inorganic fillers viz. aluminatrihydrate ${ }^{6}$, montmorrilonite, clays ${ }^{6}$, silica ${ }^{6}$ mica $^{7,8,9}$, talc $^{2,6,10,11}$, flyash $^{12}$, wollastonite ${ }^{2,6,10,13}$, kaolin, etc.

In a previous paper ${ }^{14}$ the authors studied the effect of particle size of mica on properties of nylon 6 . In this investigation flyash mixed in different weight ratios, were added to nylon 6 polymer and characterized for mechanical, thermal, dielectric, rheological and morphological properties. Use of flyash as a filler ${ }^{15-18}$ is not new. Flyash is a fine ash byproduct commonly produced by the combustion of coal during the generation of electrical power. The flyash is separated from the hot flue gases before it escapes into the atmosphere. The inorganic oxide ash is generally spherical in form. The results of many experimental studies conducted with flyash have shown that the addition 
of flyash filler does increase the stiffness of a plastic formulation, but similar to most fillers, it reduces impact resistance. Flyash offers a significant economic advantage over competing fillers, such as calcium carbonate, but does tend to impart a grayish color to the plastic formulation (to a degree dependent on the unburned carbon concentration).

\section{Experimental}

Matrix material Nylon 6 was obtained from M/s Nirlon India ltd, Mumbai.Flyash of different particle sizes as given in table 1 was obtained from M/s B.S.Mica, Mumbai, India.Flyash was added to Nylon 6 in 5, 10, 20,25,30,35 and $40 \%$ wt/wt ratios. Filler additives viz.dispersing agent (1.5wt\%), antioxidants (1wt\%) and heat stabilizers (1 wt\%) were added and was obtained from M/s Fine Organics and M/s Ciba Specialty chemicals, Mumbai, India respectively.

Table 1: Material used, suppliers list and physical properties of the matrix and the filler

\begin{tabular}{|c|c|c|c|c|}
\hline $\begin{array}{c}\text { Material } \\
\text { used }\end{array}$ & $\begin{array}{c}\text { Avg.particle } \\
\text { size } \\
(\mu)\end{array}$ & $\begin{array}{c}\text { Particle size } \\
\text { distribution } \\
(\mu)\end{array}$ & $\begin{array}{c}\text { Specific } \\
\text { surface area } \\
\left(\mathrm{m}^{2} / \mathrm{g}\right)\end{array}$ & $\begin{array}{c}\text { Density } \\
(\mathrm{g} / \mathrm{cc})\end{array}$ \\
\hline \multirow{2}{*}{ Nylon-6 } & --------------- & ------------ & ------------- & 1.16 \\
\hline \multirow{2}{*}{ Flyash } & $8 \mu$ & $\begin{array}{c}1.096- \\
416.868\end{array}$ & 1.69 & 2.3 \\
\cline { 2 - 5 } & $60 \mu$ & $\begin{array}{c}0.417- \\
724.436\end{array}$ & 0.34 & 1.99 \\
\hline
\end{tabular}

The composite granules were prepared by using twin- screw extruder (M/s APV Baker, UK, and Model: MP19PC). In this process, the temperature profiles in the barrel were $200^{\circ} \mathrm{C}, 220^{\circ} \mathrm{C}, 230^{\circ} \mathrm{C}, 240^{\circ} \mathrm{C}, 250^{\circ} \mathrm{C}$ from hopper to die. The screw $\mathrm{L} / \mathrm{D}$ was 25 and screw rotation rate of $60 \mathrm{rpm}$ was used. Tensile, Flexural and Izod impact samples (according to ASTM D-638 M91, ASTM D 790 and ASTM D 256-92 respectively) were prepared using an injection molding machine (M/s Boolani Engineering, Mumbai) with a barrel temperature of $220^{\circ} \mathrm{C}, 250^{\circ} \mathrm{C}, 280^{\circ} \mathrm{C}$. Uniaxial tensile tests were carried out using Universal tensile testing machine LR 50k from Lloyd instruments ltd.U.K at a cross head speed of 50mm per minute. The impact test was carried out at room temperature using an Avery Denison impact tester. Heat distortion temperature (ASTM D 648) was measured using Davenport Vicat Softening point instruments ltd.U.K.Dielecric strength (ASTM D 149) was measured (using a $2 \mathrm{~mm}$ thick composite sheet) by Zaran electrical instruments (input: 240V, 50Hz, 1PH; output: 0-50kV; capacity: 100mA; rating: $15 \mathrm{~min}$ ). Rheological properties of different compositions were measured using Haake RT 10 Rotovisco (Germany) parallel plate viscometer. 


\section{Results and Discussions}

\subsection{Effect of particle size of flyash on Mechanical properties of Nylon 6 / flyash composite}

It was observed that as the concentration of filler increased tensile strength decreased. The rate of decrease of strength was higher when larger particle size was used. It was also observed that the percentage elongation decreased drastically on addition of filler in both the larger and smaller particle sizes of flyash but the rate of change of percentage elongation with varying percentage of filler was higher in the case of smaller particle size as compared to larger particle size of flyash. It was also seen that at higher filler loading the reduction of tensile strength was higher in case of larger particle size. The rate of reduction of percentage elongation was higher in case of smaller particle size up to $20 \%$ filler loading whereas, it was higher at higher filler loading in case of larger particle size flyash. This variation may have been due to wide particle size distribution (p.s.d) of larger particle size flyash than that of smaller particle size flyash and at higher filler loading the interstitial volume must have been occupied by smaller particles as filler and there may have been an insufficient matrix available for contributing to the percentage of elongation. The trend of variation of tensile strength and percentage of elongation of different particle sizes of

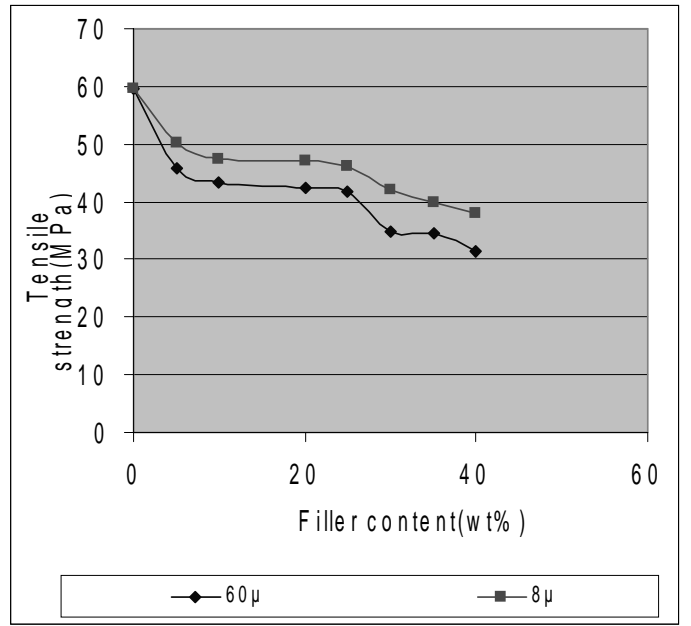

Fig. 1. Variation in tensile strength of different particle size flyash with varying concentration

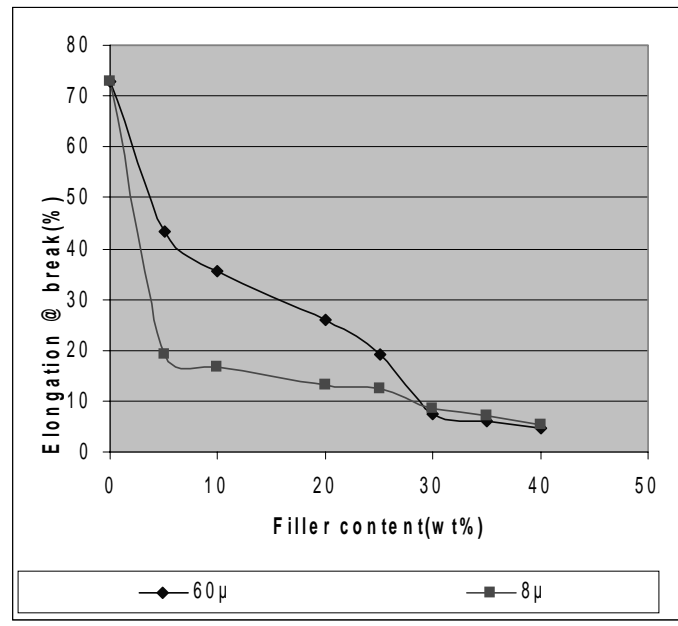

Fig. 2. Variation in elongation at break of different particle size flyash with varying concentration flyash with varying concentration is presented in Fig. 1 and Fig. 2 respectively. It was also seen that flexural strength increased with an increase in concentration of filler loading in both the cases whereas the rate of increase in flexural strength was higher when smaller particle size flyash was used. It was observed that flexural strength increased and attained maxima at lower filler concentration when smaller particle size flyash was used as compared to larger particle size flyash. This may have been due to agglomeration of smaller particle size flyash after certain concentration. In the case of larger particle size (wide p.s.d) the smaller filler particles occupied the interstitial volume 
and hence the surface area available for deformation force was higher in the case of a smaller particle size than that of larger particle size (wide p.s.d) material. The phenomenon of agglomeration and surface area of filler available was also confirmed by early onset of flexural strength decreasing in the case of smaller particle size flyash as compared to larger particle size flyash. It was also clear that at higher concentration the flexural strength was almost same in both of the cases, which may be due to insufficient matrix available for encapsulating individual filler particles and agglomerates. The flexural modulus increased continuously with increasing concentration of filler loading of both the smaller and larger particle sizes where as at higher loading for larger particle size the values of flexural modulus was more than that of smaller particle size filler indicating phenomenon of agglomeration of smaller particle size filler than that of larger particle size filler. The flexural modulus was reduced by addition of higher concentration of filler (40\%) for larger particle size where as in case of smaller particle size the flexural modulus continued increasing thereby indicating

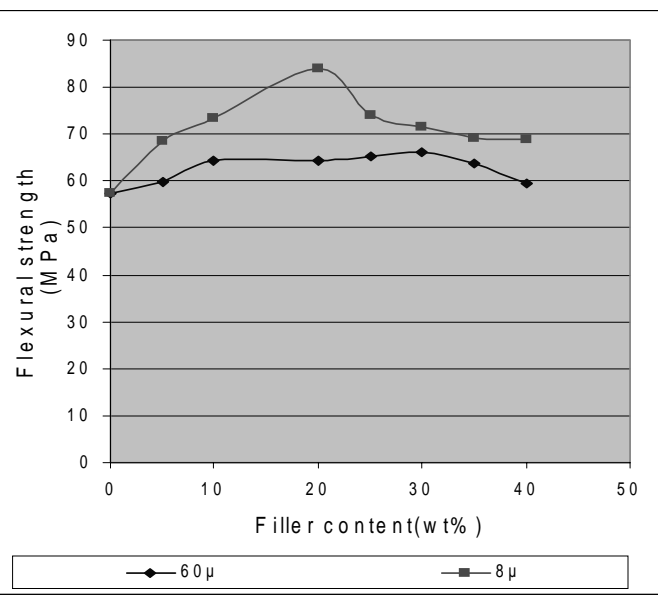

Fig. 3. Variation in flexural strength of different particle size flyash with varying concentration.

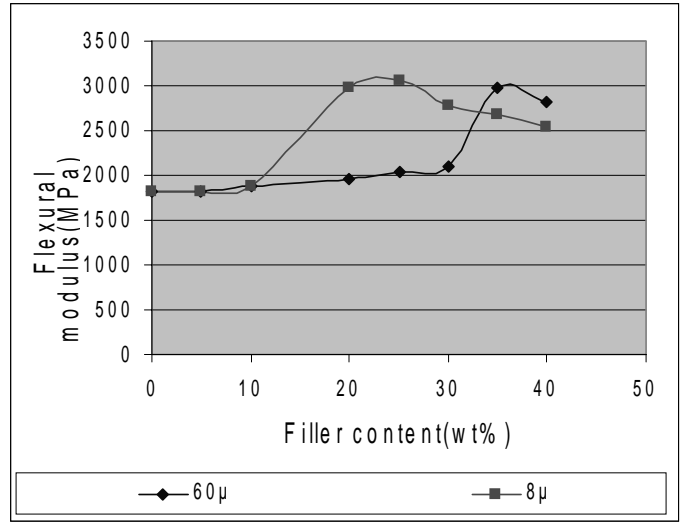

Fig. 4. Variation in flexural modulus of different particle size flyash with varying concentration that the saturation level of filler matrix composition was influenced by agglomeration. The trend of variation of flexural strength and flexural modulus of different particle sizes of flyash with varying concentrations is presented in Fig. 3 and Fig. 4 respectively. The impact strength decreased with increasing concentration of filler in the case of larger particle size flyash whereas in case of smaller particle size the impact strength initially increased or remained almost same up to $25 \%$ filler loading, which confirmed the void space available in the larger particle size material and thereby demonstrated that stress propagation was greater in the case of a larger particle size filled composites than that of a smaller particle size composites. The impact strength values of higher filler loading composites (40 wt\%) of smaller particle size as well as that of larger particle size flyash with the same filler loading were almost identical, which indicated the agglomeration of smaller particle size filler and thereby generated increasing void space, which was responsible for stress propagation. It was also observed that rate of change of impact strength was same at higher filler loading i.e above $25 \mathrm{wt} \%$ of both the particle sizes and this indicated that the total surface area available for matrix remained almost same in case of both the larger particle size and smaller particle size agglomerates. The trend in variation of impact strength of different particle size 
flyash with varying concentration is presented in Fig. 5. This assumption of agglomeration of smaller particle size filler was also confirmed by a higher rate of increase of Young's modulus in the case of smaller particle size filler than that of larger particle size filler at higher filler loading .The Young's modulus remained unchanged with the increase in concentration of larger particle size flyash up to $20 \%$ filler loading where as in case of smaller particle size Young's modulus was lower than that of virgin nylon 6 up to $20 \%$ filler loading. This variation in Young's modulus in both the cases indicated good dispersion of smaller particle size within the filler than that of larger particle size at lower filler loading. The smaller particle size filler agglomerates hence reduced the strain value by restricting the mobility of matrix chains. The mobility of matrix chains and agglomeration of smaller particle size filler is clearly indicated by the increase in Young's modulus with a higher rate than that of larger particle size filler. This was also supported by the observation of Young's modulus at $40 \%$ filler loading of both particle sizes, which was almost same.

The trend of variation of Young's modulus of different particle size flyash with varying concentration is presented in Fig. 6.

\subsection{Effect of particle size of flyash on Dielectric and Thermal properties of Nylon 6 / flyash composite.}

It was observed that on addition of flyash the dielectric strength increased drastically in both of the cases. The larger particle size filler shows a peak at lower concentration but the strength decreased and remained constant at higher loading, whereas in the case of smaller particle size, the dielectric strength increased but then

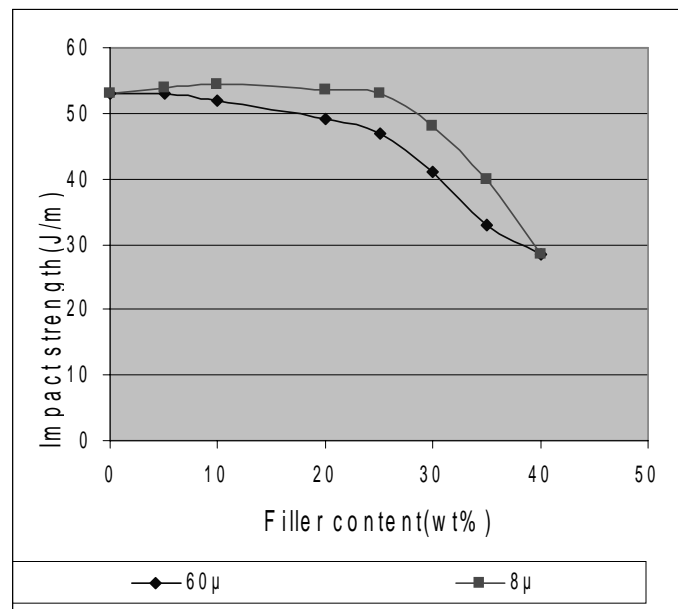

Fig. 5. Variation in Impact strength of different particle size flyash with varying concentration

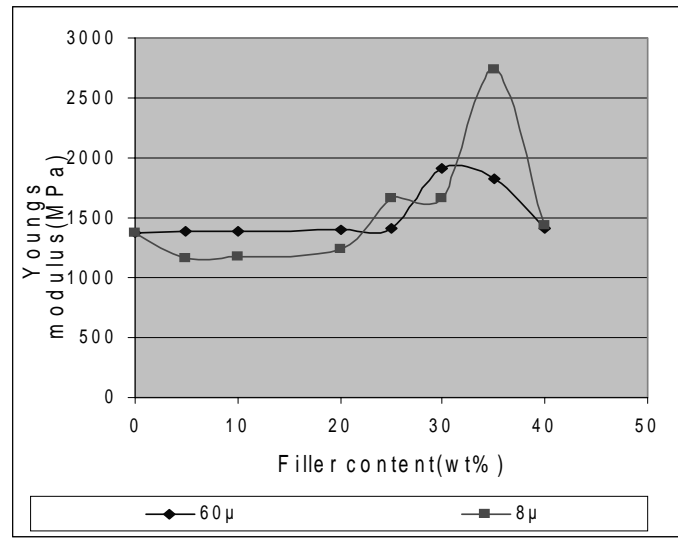

Fig. 6. Variation in Young's Modulus of different particle size flyash with varying concentration

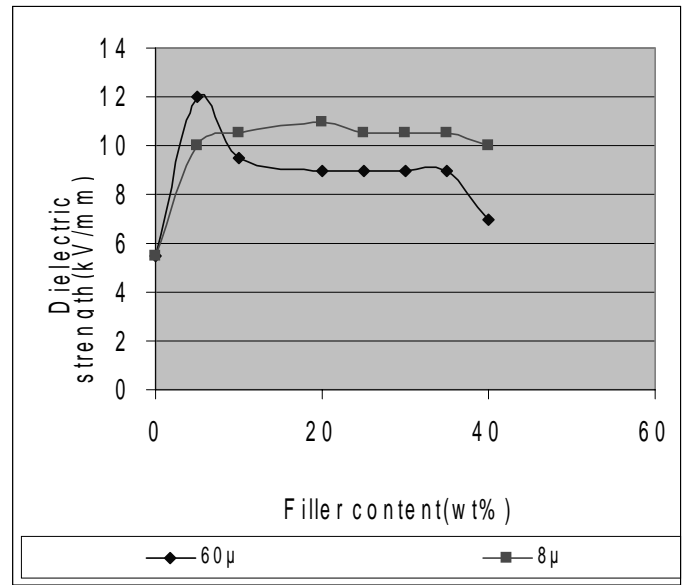

Fig. 7. Variation in dielectric strength of different particle size flyash with varying concentration 
remained almost unchanged at any concentration of filler loading. This may have been due to the leakage of current from un encapsulated interstitial filler particle at higher filler loading with larger particle size where as in case of smaller particle size there was proper dispersion which did not affect the dielectric properties. The heat distortion temperature increased with increasing concentration of filler in both of the cases. The extent of increase in heat distortion temperature at lower filler loading of larger particle size flyash filled nylon 6 composite was higher than that of smaller particle size flyash. The rate of change of heat distortion temperature was higher and gradual in case of smaller particle size filler than that of larger particle size at any filler concentration. The heat distortion temperature was higher at higher filler loading (40 wt\%) with smaller particle size as compared to larger particle size, whereas at other concentrations the heat distortion temperature was lower for smaller particle size filler composites than that of larger particle size filler composites, which indicated that at higher filler loading the extent of agglomeration of smaller particle size increased and the total surface area of filler matrix interaction remained almost same in both cases of the particle size. The trend of variation of dielectric strength and heat distortion temperature of different particle size flyash with varying concentration is presented graphically in Fig. 7 and Fig. 8 respectively.

\subsection{Effect of particle size of flyash on rheological behavior of flyash filled nylon 6 composites.}

Fig. 9 and Fig. 10 depicts the variation in shear viscosity versus shear rates at $250^{\circ} \mathrm{C}$ of $60 \mu$ flyash and $8 \mu$

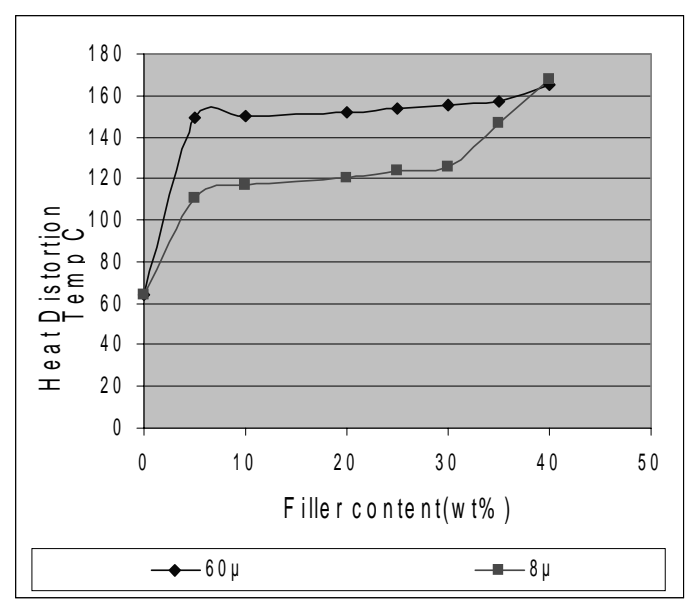

Fig. 8. Variation in Heat Distortion Temperature of different particle size flyash with varying concentration

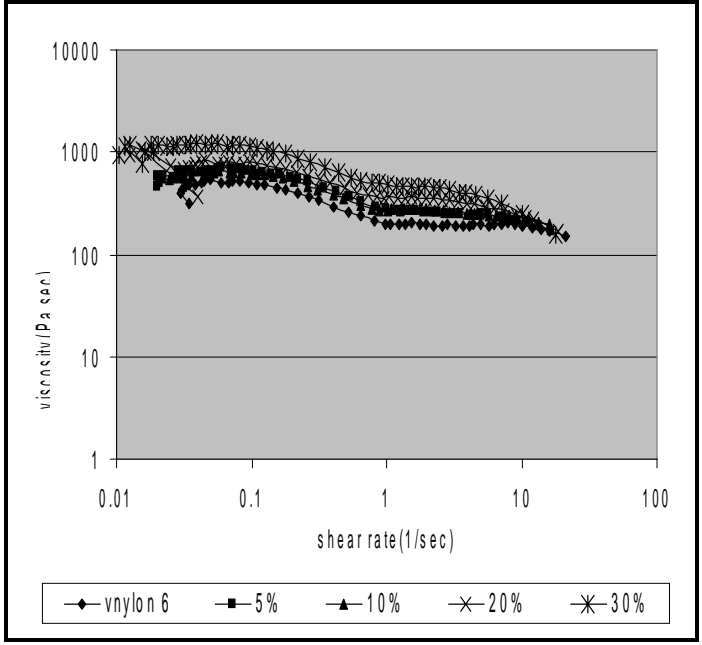

Fig. 9. Variation in shear viscosity of Nylon 6 with filler content (60 $\mu$ flyash)

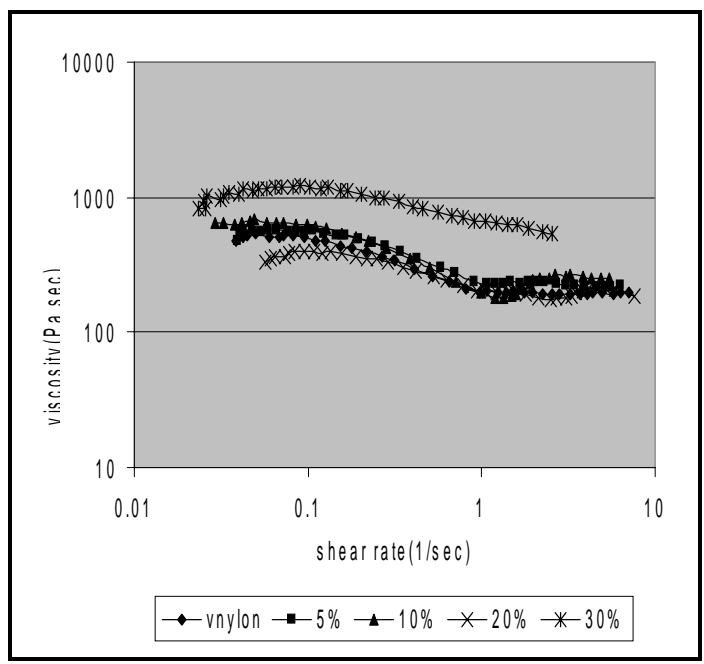

Fig. 10. Variation in shear viscosity of Nylon 6 with filler content ( $8 \mu$ flyash) 
flyash filled nylon 6 composite respectively. It was seen that addition of flyash of any particle size increased the shear viscosity but the slip of particulate filler occurred at early concentrations (at $10 \mathrm{wt} \%$ ) in the case of larger particle size flyash than that of smaller particle flyash (where the slip is at $20 \mathrm{wt} \%$ ). The increase in the viscosity may have been attributed to the properties of filler such as its maximum packing fraction. The rate of increase in the viscosity was dependent upon the ratio $\left(\varnothing / \emptyset_{\mu}\right)$ where $\varnothing=$ volume fraction of the filler and $\emptyset_{\mu}=$ Maximum Packing fraction. The flyash used $(60 \mu)$ has almost 1-2 \% hollow sphere which explains to the early slip between filler and matrix whereas in case of smaller particle size flyash even though there were no hollow spheres, the slip must have been due to the agglomerates of smaller particle size flyash and thereby causing the increase in ratio of packing fraction. For a better comparison Fig. 11 depicts the variation of zero shear viscosity at 0.1 shear rate (extrapolated values) at $250^{\circ} \mathrm{C}$ of flyash filled Nylon 6 .

\subsection{Effect of particle size of flyash on morphology of flyash filled nylon 6 composite.}

Fig. 12 and Fig. 13 presents the Scanning Electron Microscope (SEM) micrograph of $60 \mu$ flyash and $8 \mu$ flyash at $30 \mathrm{wt} \%$ filler loading respectively. It was observed that the polymer matrix was insufficient to encapsulate the individual filler particles in both of the cases. In the case of particle size, the smaller particles had occupied the interstitials volume and

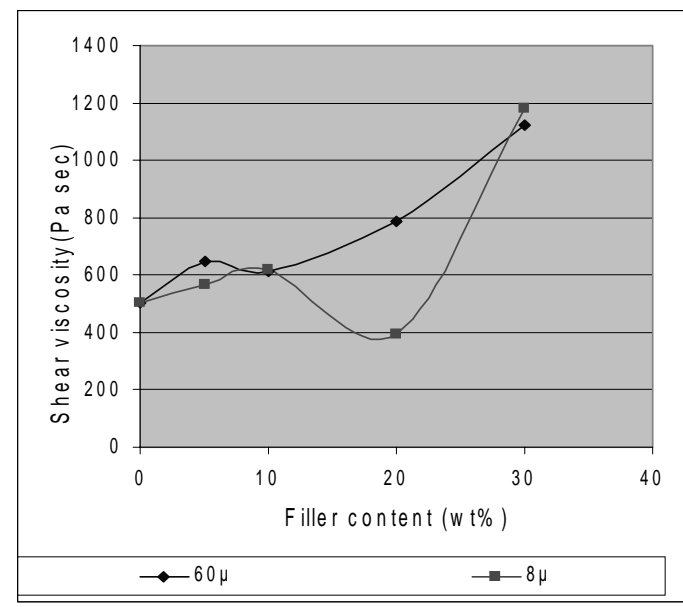

Fig. 11. Variation in zero shear viscosity at 0.1 $\mathrm{sec}^{-1}$ shear rate at $250^{\circ} \mathrm{C}$ of flyash filled nylon $6 /$ composite

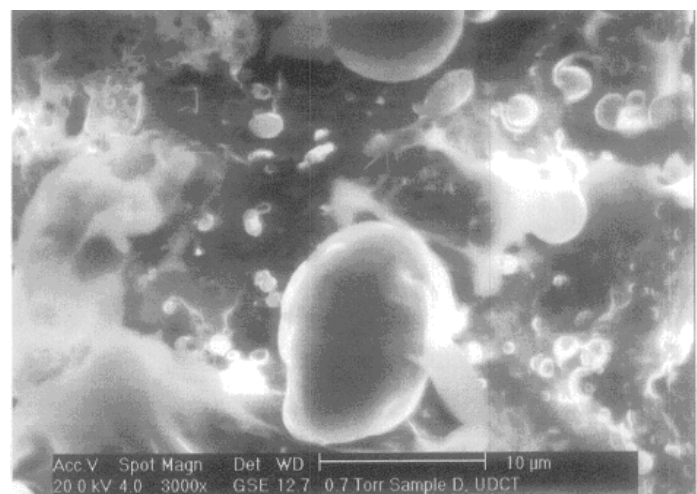

Fig. 12. SEM micrograph of $60 \mu$ flyash

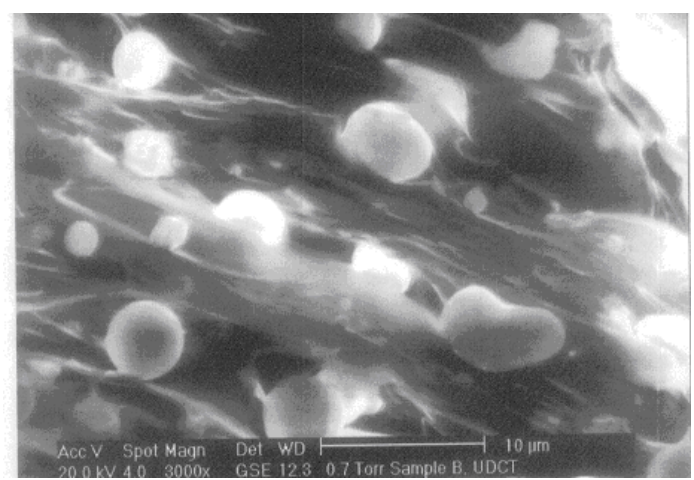

Fig. 13. SEM micrograph of $8 \mu$ flyash thereby the total packing fraction remained unchanged whereas in case of lower particle size, all the filler particles were separate but were not encapsulated. Thus the total surface area at $30 \mathrm{wt} \%$ filler loading at larger and smaller particle size remained almost the same, thereby the total filler matrix interaction forces remained the same due to melt viscosity which remained the same as can also be seen from the Fig. 9 and Fig. 10. 


\section{Conclusions}

- The larger particle size flyash showed improvement in mechanical properties on increasing concentration of flyash as compared to lower particle size but the lower particle size flyash showed improvement in dielectric properties as compared to larger particle size flyash.

- Inorganic fillers such as flyash added to the polymer improved their rigidity, heat resistance, and dimension stability.

- A significant increase in the heat distortion temperature was found with increase in the filler loading as in the case of both the particle size.

- Thus the mechanical property of composite is a function of the particle size, the dispersion, the particle orientation, the interfacial interaction between the minerals and the polymer matrix.

\section{References}

1) Maiti, S.N; Lopez, B.H; J.Appl. Polym. Sci., 44,353(1992).

2) “Nylon Plastics”; Kohan, M.I, Hanser: New York, 1973.

3) “Modern plastics Encyclopedia Handbook”; Mc Graw Hill; New York, 1994.

4) Harper, C.A,”Handbook of Plastics, Elastomers and Composites”; Mc Graw Hill, New York, 1996.

5) Berins, M.L, S.P.I,"Plastics Engineering Handbook”; Chapman and Hall; London/Newyork, 1974.

6) Nielsen, L.E, "Mechanical properties of Polymers and Composite"; Marcel Dekker; New York, 1974.

7) Watari, T; Yamane, T; Moriyama, S; Torikai, T; Imaoka, Y; Suchiro, K and Tateyama H, Mater. Res. Bull, 32,719(1997).

8) Cheng, L .P; Lin, D. J and Yang, K. C, J. Membrane. Sci., 172, 157(2000).

9) Vaia, R.A; Price, G; Ruth, P.N; Nguyen, H.T and Lichtenhan, J, J. Appl. Clay. Sci, 15,67(1999).

10) Gachter, R and Muller, H,”Plastics Additives Handbook”, Hanser Gardner Publication Inc, Cincinnati, 1993.

11) Hess, K.M, Kunststoffe, 73,282(1993).

12) Xing, Z, Fuel and Energy Abstr, 37,185(1996).

13) Tanaka, H, J. Polym. Eng. Sci., 39,817(1999).

14) Suryasarathi Bose and Mahanwar, P.A, Journal of Minerals \& Materials Characterization \& Engineering, 3(1), 23( 2004)

15) Technical Bulletin, American Coal Ash Association, Alexandria, VA 22314-4553 (1999).

16) Technical Bulletin, Southeastern Flyash Co., West Columbia, S.C. 29169.

17) Jones, J. et al., SPE Annual Technical Conference, 41, 3594 (1995).

18) Shut, J, Plastics Technology, 45(9), 42(1999). 